\title{
Activating Activism Within the EdD: Connecting DiP Research and the Community
}

\author{
Joy Howard, Ph.D. \\ University of Southern Indiana \\ joy.howard@usi.edu \\ Timberly L. Baker, Ph.D. \\ Arkansas State University \\ tibaker@astate.edu
}

\begin{abstract}
In this paper the co-authors discuss and describe the challenges of community engaged scholarship. Using an ongoing long-term project about the school prison nexus as an exemplar, the authors propose ways that EdD student DiP's can be connected with the community. Lessons learned and implications for other EdD programs are shared.
\end{abstract}

\section{KEYWORDS}

dissertation in practice, community-based research, activism, critical race praxis

As an instructor of a qualitative research class with students from our community-based educational leadership EdD program, I, Joy, introduced several different research methodologies including community-based participatory action research (CPAR). A student in the class with a strong commitment to social justice asked about how she could use this framing for her dissertation work but reported that she was not presently engaged in any activist projects in the community. I told her that because of ethical, logistical and temporal factors, it would be improbable to take this research approach if she was not already involved in a work-in-progress coming into the program. My response made me consider the tension of trying to engage students in meaningful work within the context of a four-year program (see Fine, 2018; Laura, 2014; Noblit, 2004). The question stuck with me though, and I was troubled by my honest but incomplete answer. In this paper, we as co-authors, discuss a method of engaging EdD students in CPAR work through their dissertation in practice (DiP) projects in an ethical and sustainable way. We offer an example of a long-term project to abolish the school prison nexus in a Midwestern community that began in 2018 as a community-based project where DiP work could be ethical, useful, and the sustainability of the university-community partnership remains intact after the student researchers finish their programs.

In this paper, we consider ways to activate activism in an EdD program through building and sustaining a research team of doctoral faculty, students and community activists who are genuinely engaged in the process of activist projects. In our conceptualization of scholarly activism there are several characteristics that are nonnegotiable. That is, academic activism must be (1) validated by the community, (2) sustainable, (3) malleable, and (4) methodologically aligned with the goals and purposes set by the community. We take up these four elements in this paper as we use our scholarly-activist work on racial justice for Black children.
New articles in this journal are licensed under a Creative Commons Attribution 4.0 United States License. Program and is cosponsored by the University of Pittsburgh Press.
We offer our project, AndHowAreTheChildren (AHATC), as a work-in-progress example of activism embedded within an EdD program. The objective of this research team is to train and mentor EdD students through classroom pedagogy and participation as part of a research team. The hope is that these emerging community engaged scholars have an opportunity to complete a DiP representative of their desire to do scholarly work that prioritizes justice in and through educational research. Through our work with/in a community and intentional network-building process, there are opportunities for a diverse group of EdD students to engage in research that celebrates their passion for research while also honoring their connections to community as scholarly practitioners. In this case, some students are already a part of the ethos of the community, for others, they are coming as perceived outsiders. CPAR is a process whereby community members and researchers share co-equal roles to work toward equitable outcomes for realworld problems that effect real people who are a part of social institutions and systems. CPAR demands genuine partnerships between researchers and community stakeholders in the form of knowledge sharing and measuring outcomes. Success of these projects is in/validated by the community.

In what follows we first offer a conceptual framework for working with EdD students to engage in racial justice work. Second, we discuss the methodology of our work including our positionality. Third, we provide the context of the work within a Midwest city, and finally we discuss lessons learned which includes recommendations of this work for others.
This journal is supported by the Carnegie Project on the Education Doctorate: A Knowledge Forum on the EdD (CPED) cpedinitiative.org impactinged.pitt.edu Vol.6, No. 1 (2021)
ISSN 2472-5889 (online) DOI 10.5195/ie.2021.162 


\section{CONCEPTUAL FRAMEWORK}

Constructing an organizational framework for the work that social justice entails is both daunting and messy, yet it is both essential and necessary. We take on this challenge by discussing the literature that informs our understanding of activism and social justice as it can be implemented in an EdD program in general and then more specifically through the dissertation in practice (DiP). We then move on to address our praxis, which we frame through Critical Race Praxis (CRP) and CPAR as these two are intertwined in our implementation of preparing community-based educational leaders through an EdD program. We then end the section by discussing our own positionality in this work, as it informs the way we move in this work as researchers, EdD faculty, and scholars.

\section{Review of Literature on Activism and Social Justice in the EdD}

In 2017, the Impacting Education Journal published a special issue devoted to issues in education in the 21 st Century. Several authors highlighted an emphasis on social justice in EdD programs. There are a few key themes that directly inform the ways that we think about activism in the EdD Those are: a caution for the disparate ways that social justice and activism are defined in academia, the call for authentic community engagement, and the strength of action research methodologies.

Social justice as a construct has been taken up by institutions and academicians across the country in disparate and even divisive ways (Strom \& Porfilio, 2017). Our framework for social justices is derived primarily from Gloria Ladson Billings (AERA, 2015) who interrupts the milieu of interpretations and reorients us to focus on "justice, just justice." Similarly, Four Arrows (2017) asserts that social justice is "inseparable from ecological justice, sustainability and diversity" (p. 28). In other words, we cannot operate in silos or oversimplify the ways that in/justice plays out in communities, schools, and in the everyday lived experiences of individuals. In this call toward justice, EdD programs can play an important role in connecting classroom counter-hegemony to real-world education, including incorporating community project-based learning as part of coursework and even dissertation work (Four Arrows, 2017). Considering this we approach the possibility of social justice being moved into the EdD classroom.

Taking a turn from the status quo of EdD programs requires courage, determination and imagination and it demands that academics step outside of the confines of universities and engage in genuine ways with community (Four Arrows, 2017). As Lupinacci (2017) so aptly asserted, this work requires that "educational leaders must aspire to being cultural workers, respected and disciplined researchers, effective and engaging speakers, and must both talkthe-talk and walk-the-walk" (p. 24). Engaging with community, forging healthy relationships between universities and local people groups and/or neighborhoods has a long and fraught history that is beyond the scope of this present discussion (see Noblit, 2004). While there are plenty of "social justice" efforts made by researchers, programs, and institutions, the execution and results of these efforts often fall short of the mark of justice. Lupinacci (2017) warned:

It is one thing to say you are committed to social justice and sustainability, but it is another thing entirely to take on addressing, examining, and proposing solutions to inequities in education, society, and the cultural belief systems undergirding the vastly experienced day-to-day violence of oppression and domination of poverty, sexism, racism, ableism, and speciesism. (p. 25)

This is a formidable challenge for EdD educators to be courageous and committed to social justice and to infuse addressing oppression into both our curriculum and our lives.

With this challenge in mind, the question becomes, how do we proceed with both caution and courage? One promising challenge is our teaching and mentorship in the EdD context. As faculty charged with the preparation of educational leaders to become well-equipped scholarly practitioners able to meet the educational challenges of the 21 st century, we are obligated to "have the courage necessary to teach others that they must be transparent in their commitment to eliminating social inequalities, environmental degradation, over policing, and militarization harming our world and planet" (Zinn, 2002 as cited in Strom \& Porfilio, 2017, p. 16). One avenue for activating this instruction and commitment is through the methodologies that we expose our students to in the classroom, and the ways that we model this work through our own scholarly inquiries. We agree with Lupinacci (2017) who emphasized community engagement and methods that draw heavily from Participatory Action Research (PAR) and Youth Participatory Action Research (YPAR). For us this meant the use of CPAR as our framework for engagement.

Explicitly defining and demonstrating social justice in the context of an EdD program is complex. Porfilio et al. (2019) addressed preparation of $\mathrm{K}-16$ leaders in education doctorate programs that attempt to operationalize social justice. They offer two case studies of programs, as a way to enter the conversation about operationalizing social justice, rather than offering a template or example of how to do this work. They emphasize the imperative of social justice in EdD programs such that in “...today's socio-historical moment in the US, there are more children than ever living in poverty, public schools are underfunded, and urban communities are fighting to keep their schools open. Therefore, it is more critical than ever to prepare teachers and leaders to work for social justice in educational settings" (p. 104). Porfilio and co-authors (2019) defined social justice in the context of the EdD programs. They continued to discuss the importance of why socially just leaders are needed and what knowledge and skills they need. They determined that programs need:

1. An explicit discussion of a specific social justice stance.

2. To address the tension between coping with current neoliberal trends, such as pressures of accountability systems and systematic defunding of public schools, on the one hand and working to address systemic inequalities on the other.

3. To examine the ways they actually enact the named social justice orientation within their program (i.e. program curriculum).

4. To define through cited research their social justice stance and the programmatic choices that support that definition. (pp. 104-105)

The authors continued naming scholars that have essentially "made it clear that educational leadership must be viewed as a transformative cultural practice" (p. 105). Ultimately, Porfilio et al. (2019) argued that the preparation of socially just educators and leaders must be "framed around questions of equity, ethics, and social justice to bring about solutions to complex problems of practice" (Porfilio et al., 2019, p.104). We relate to the work of 
Porfilio et al., who "also argue that understandings of social justice must be aligned with the research methodologies that are taught in the doctoral programs" (p.107). Our project aims to do this for students making direct connections between their classroom learning and their CPAR work as leaders/researchers with community working groups.

We operationalize the elusive construct of social justice through our NVW work as we invite community into the process of partnering with researchers to address the concerns of the community. We do this by letting the desires of the community guide the research rather than an a-priori naming of the research goals and questions of research. This ground up approach, as much social justice work requires, means that those that are most impacted by the lack of justice inform the next steps of the research. In doing so the community creates what characteristics of the issue will be examined.

\section{Addressing Social Justice as a Problem of Practice}

George (2017) discussed the need to examine the characteristics of EdD programs that are preparing higher education professionals to have and sustain a social justice orientation. Ultimately, George applied the framework developed by Capper, Theoharis, and Sebastian (2006) Toward a framework for preparing leaders for social justice as a structure to determine effectiveness and implementation of a social justice EdD for higher education professionals. Using the Capper et al. (2006) framework, George (2017) applied the framework to an unnamed graduate program at an institution that is a part of CPED. Specifically, George discussed the DiP. The DiP is of particular interest as it is defined as a capstone project that requires students to "address a meaningful problem of practice" (p. 46). "The project is also conducted in consultation...[with] those stakeholders--who notably have a vested interest in resolving the shared problem...serve as contributors to and/or members of the DiP committee" (p. 46). Furthermore, George discusses why the DiP is undertaken in order to address social justice. The DiP allows greater perspective in answering a question as well as helping students to "(a) understand and fully appreciate the broad (and in some cases conflicting) stakeholder perspectives that exist around a socially pressing issue of practice in higher education and (b) contemplate authentic and socially democratic ways to communicate with and engage those stakeholders in key decision-making processes focused on lasting resolutions" (p.46). Moreover, the DIP is taken up in three stages within the program that the framework is applied to including:

1. a detailed literature review, then after more coursework;

2. a methodological selection is made that makes sense for the analysis of the problem of practice that is chosen; and

3. then they write a prospectus of the research work. As the author stated, "the intended purpose of the DiP is to raise student's consciousness about structural and systematic inequities resulting from ineffective....practices" (p. 47).

In our own practice the DiP is the capstone form of the students CPAR work with community. As previously stated, the work EdD students are doing by partnering in community working groups and allowing the community to determine the questions of research that are explored there is "address[ing] a meaningful problem of
practice”(George, 2017, p. 46); while simultaneously “...rais[ing] student's consciousness about structural and systematic inequities resulting from ineffective...practices" (George, 2017, p. 47). This process is an opportunity to create a space where EdD students can refine their skills as community engaged scholars, while making practical and productive contributions to bettering their community.

Demonstrating social justice in an EdD has its challenges, yet attempts at doing social justice in an EdD will push our field to develop students and research that advances justice. As a result of explicitly defining the development of social justice leaders, social justice can be advanced through EdD programs. Engaged work and the completion of the DiP's can meet the needs of a doctorate as a capstone and address a problem of practice within a community. The development and implementation of social justice through an EdD is possible, and we offer our edition of how we seek to do this. We take up critical race praxis (CRP) as a starting point for framing our approach to social justice in our EdD programs through the use of a DiP.

\section{Theory: Critical Race Praxis}

In viewing this work through critical race praxis (CRP) one would consider that we must wrestle with the endemic nature of racism (Jennings \& Lynn, 2005) as well as the ways in which race cannot be ignored in the context of CPAR and our student's work. We must also address and eradicate the too common "researcheras-colonizer" in order to move us toward social justice CRP and its benefits. We must address a justice condition and through the use of CRP as a framework for success in implementing CPAR. The following section attempts to frame CRP broadly so as to provide an understanding of CRP and then more specifically how it helps us to prepare social justice leaders through an EdD program.

In a 2020 interview with David Stovall (CRSEA, 2020)academic, community scholar and CRP implementor; he discussed four elements of CRP; first by defining praxis as "action and reflection in the world in order to change conditions." Stovall offered conceptual concerns, material concerns, performative concerns, and reflexive concerns as the conceptual framework for CRP. Through these four avenues, educators in partnership with communities, can disrupt attempts to dehumanize and rob people of their right to address injustices in our communities to work toward a justice condition. The conceptual concerns are identified by seeking to build an understanding in order to engage in critical analysis to be able to see the condition and identify folks you can work with to change the condition. Material concerns, include accessing both the materials needed and utilizing the networks of individual(s) who can get those materials in order to address adverse conditions. Performative concerns are actions( in real time, not the delayed response time common in academia) that use the materials that need to be taken up in response to the critical questions identified in regard to an oppressive condition. Performative is also the activities performed that become the assessment of the progress toward addressing the condition. CRSEA (2020) interview moved on to discuss reflexive concerns which is asking and reflecting on the questions "What have we done that worked well and what do we need to improve that did not go well?" These are the tangible things that are working toward changing the identified human condition. Stovall's discussion of CRP provides a framing of the ways in which CRP can work at multiple educational levels, yet we apply it to the EdD. 
CRP theoretically guides our conceptualization of the process and learning that occurs both with graduate students and with the community they are partnering with for the work. We engage CRP in a specific way, as we imagine the possibilities of CPAR. The DiP model allows our graduate students scholarly engagement to take the form of community organizing (i.e., Baldridge, 2020; Kirshner, 2015), pedagogy in informal learning spaces (Baldridge et al., 2017), curricular planning and vision (Love, 2014), public scholarship (Torre, 2009), leadership practices (Horsford, 2012), and spacemaking (i.e. protests, refusals, artistic expression) (Douglas \& Peck, 2013, Lysicott, 2014). We visualize CRP as the iterative work of applying tenets of Critical Race Theory (Ladson-Billings \& Tate, 1995) by reflecting upon and revising curriculum as well as implementing pedagogical and curricular changes in order to build an individual's capacity to resist racism. Our approach to addressing issues of race and justice are intertwined and require a participatory way to critique, reflect and improve outcomes for graduate students and for the populations with whom they work. We as graduate educators are engaging a justice condition, while concurrently teaching, partnering with, and engaging our students in addressing a justice condition. We conceptualize CRP as the symbiosis of theory, reflection, and practice (Freire, 2000), and more specifically (CRSEA 2020; Stovall, 2006; Yamamoto, 1997) as the ways in which we work with our community, graduate students and selves to struggle toward liberation (Friere, 2000). As practitioners of CRP we view it as moves that "counter systemic, institutional, and individual racism through continual action, reflection and re-inventions of strategies that work against power structures and practices which dehumanize people based on race" (Baker \& Howard 2020, in press). This definition is implemented in our work to address a justice condition, to prepare social justice leaders, and to prepare scholars who can partner with community to address a justice condition.

\section{Methodology}

Drawing from a Critical Race Praxis framework, we mentor and instruct doctoral students in ways that exemplify activist scholarship. We teach and demonstrate the use of CPAR as a methodology. To begin, we draw from Warren's (2018) explanation of critical community engaged scholarship which requires that researchers partner with community, parent, youth, and educator groups to pursue change that is focused on increasing equity and justice in education (Oakes \& Rogers, 2005). Further, we agree with Johnson (2018) who described community-based participatory research as a process where community members take a co-equal role with trained researchers and professionals in four ways. Community members (1) identify and define a problem to be studied, (2) define values and principles that distinguish one way of knowing about the problem from another, (3) generate characteristics of the problem that allow identification of alternative courses of action and attributes by which to assess progress toward an improved state, and (4) define criteria by which one might determine that a new way of doing things generates, or is likely to generate outcomes that represent improvement over the status quo. This approach aligns well with George (2017) who used the language of "consultation of stakeholders" reiterating the need for a connected community approach.

As instructors, mentors and lead investigators in the research process, we aim to model and revisit the aforementioned core principles relative to activist scholarship consistently. That is, activism must be:

1. validated by the community, not academia as the "experts" in activism- in other words, to whom are you accountable (Patel, 2016);

2. long-term, not temporary or predatory as has too often been the trend in academic research;

3. open to new and difficult narratives that redefine research methods, directions, and representation;

4. engaged with diverse methods of qualitative and quantitative data collection and analysis aligned with the goals and purposes set by community activists.

Given this understanding, there is a great variety of methods that can be a part of a CPAR design in terms of data collection, analysis, and ways to represent findings. The methods should be responsive to the goals and foci of the community to whom we are accountable. In the case of this research team, we have been very clear that the community to whom we are accountable to for the value of our work is Black youth and families.

\section{Position in the Work}

Joy. As a white ${ }^{1}$ activist qualitative researcher who is primarily focused on anti-racism in education, I am always learning, interrogating, and teaching from an in-process perspective. I engage in this work as a motherscholar with three Black mixed-race boys whose schooling experiences and educational opportunities are profoundly affected by a racist educational debt (AERA, 2015) that remains today. My experiences as a teacher educator and instructor of educational leaders has meant that my pedagogy is informed by the reality that I have and will continue to teach the educators that my sons learn from in school. As a result, I share my own limitations, blindspots, solidarity, and discomforts with my students as a learning opportunity. In my work in the classroom and the community, I am motivated by the hope that it is possible to create learning spaces where Black students can thrive. It is with this in mind that I have engaged in the initial stages of planning for, recruiting students to, and teaching in the EdD program at the University of Southern Indiana since 2015, and taking an active role in community organizations in our Midwest community that prioritize racial justice in both their missions and actions.

Timberly. When examining issues of social justice, I am situated as both a participant, learner, and instructor. I identify as one that actively engages in social justice work, as a motherscholar, more specifically I work toward justice for students of color and those identified within special education. The personal of the motherscholar identity means that I do not disconnect my orientation of preparation of leaders from the question, "Would I want this person, leading, or teaching in the school my children attend?" "Are they a trusted ally of people of color?" As a professor in an EdD program I have agency and responsibility to students to prepare them to understand and enact social justice, yet the EdD program itself is not set up to easily undertake this endeavor. This disconnect between my personal identity and that of a program that is developed to prepare leaders means that I struggle to enact my social justice orientation more explicitly in my courses. Yet my own articulation of work and choices about course content and foci does demonstrate this commitment even if in small ways. Previously, I was a member of the faculty at the University of Southern Indiana (USI) beginning in 2015 and ending in 2017, yet my ties to the 
community and the work of improving educational outcomes for Black youth and families remains situated within our Midwestern community.

Co-researchers and co-conspirators. As co-researchers and personal friends, we have developed a deep trusting relationship as co-teachers, co-authors, and auntie figures to each other's children. This is important to mention because the depth of our relationship strengthens our ability to work through conflicts that arise as an outgrowth of CPAR projects-such as finding common times to meet, agreeing upon project-related tasks, sharing the work load, determining authorship, hosting challenging conversations with community members and/or students, or co-facilitation skills in dynamic community spaces. It is also important because our partnership demonstrated in co-facilitation, co-teaching and coauthorship models for students' skills and dispositions necessary in cross racial collaborative work that can be strengthened by dissenting opinions, diverse perspectives and mixed methods of data collection and analysis.

To illustrate some of the diverse methods used, we later explain our initial reports and why we chose the methods that we did. Next, we will discuss the current stage of the process where we are mentoring a team of EdD students in the CPAR methodologies grounded in Critical Race Praxis (CRSEA, 2020). Finally, we offer possible directions that doctoral students will take with their DiP based on the direction of community organizers and activists.

\section{COMMUNITY ENGAGED SCHOLARSHIP IN A MIDWESTERN CITY}

A fair amount of contextualization is needed before we can describe the current stage of this project and what we have learned thus far. The project we have named, AndHowAreTheChildren, is based on ongoing community-based research that formally began in 2018. Timberly was called upon to compile a quantitative report about the disproportionalities in school discipline by the local Commission on the Social Status of African American Males. In a public forum, Timberly highlighted some of the major findings that demonstrated clear racial disparities in the areas of suspension, expulsion, and arrests for Black and Multiracial youth. During this public forum, community leaders and concerned citizens from the Black community of this Midwestern city voiced the need for community action and responsibility to interrupt these inequities. As a result, Joy, who has experience in CPAR began a conversation with Timberly, members of the Commission, and local leaders about the potential for a CPAR project to be designed in response to the demand for action. In 2019, with a small grant and an undergraduate research assistant who is actively engaged in the community, we hosted four "community conversations" soliciting the participation of the "families of Black and multiracial students in a Midwestern city." These community conversations were hosted at local non-profit organizations in different parts of this city in spring 2019. The focus of these conversations was to discuss the challenges and potential solutions for working toward equitable change. The outcome of these meetings was to identify six specific areas for community action: police in/and schools; community investment; parent involvement; curriculum, pedagogy and faculty of color; mentors; and policies and funding. In fall 2019, Joy organized a public forum in the center of the city to issue the report (printed out and highlighted verbally). The aim of these meetings was to attempt to organize working groups (e.g., Mentors) for each theme led by a group of diverse community members (each group has at least three members of a leadership team) which included university faculty, retired military veterans, political leaders, clergy, barbers, legal counsel, parents, teachers, and non-profit employees to name a few.

In 2020, we have continued to move toward building synergy in and between the working groups. For example, this was demonstrated by a National African American Parents Day celebration in February at a local Black church, the launch of a Facebook page with hundreds of followers, the organization of book clubs focused on curriculum and pedagogy supportive of African American students specifically (see Lyiscott, 2019; Boutte, 2016). At the same time, this network building has been met with very real challenges that are common to all community-based work (e.g., organization, dissenting opinions) but most notably the very real and very novel set of issues related to COVID-19. That is the question of-how to engage in community activism in the time of social distancing? One specific example of the disappointment and dissonance that this has caused in the community engaged work is the fact that we had planned a dynamic city-wide "First Annual African American Children's Literacy Festival" (The LitFest) on April 12, 2020. Due to COVID-19, this had to be cancelled. Given the financial support promised by institutions that are now in crisis, the intention of including hundreds of individuals in a multi-generational crowd, and the use of buildings and equipment that may be closed indefinitely, the idea of this event happening in the near future is unlikely. These realities, the dynamics, im/possibilities, messiness, disappointments, and collaborative endeavors are all a part of critical praxis.

Despite these challenges, we respond to Lupinacci's (2017) call to confront dominant perceptions of what currently constitutes leadership and instead "work to (re)constitute toward a leadership that takes serious social justice and sustainability" (p. 26). Therefore, with the support of a small grant from the University we are moving forward with a focus on identifying effective strategies for building a community-wide network to destabilize the school prison nexus in a Midwestern city.

In this current phase, Joy secured a small grant that is primarily geared to support the formation of a research team, comprised of five EdD students and two Co-Pl's (Joy and Timberly). The grant will also provide some initial start-up funds for incidentals that may come up for different working groups. Each EdD student was selected based on their research interests relevant to justice in education and demonstrated long-term engagement with the community. The concept is that each research assistant will be assigned to a group that best correlates to their research interest. The research assistant will help to organize and document the goals and action steps of the working groups as an initial function in the larger project. The longterm goal, however, is that the EdD students will write a DiP that will in/directly correlate to the identified needs of the community in working to destabilize the school prison nexus in a Midwestern city. For example, one research assistant (who is also a teacher) is working with the curriculum, pedagogy and faculty of color group and is co-facilitating a book club discussion about culturally sustaining pedagogy with Joy. Based on themes from community conversations in 2019, there was an identified need to provide focused professional development that specifically supports teachers in developing their skills and knowledge of culturally sustaining pedagogies for Black children. Given the coalescence of the community and research assistant's interests, the idea is this student's DiP will be a direct answer to a community need. 
This type of structure of community identified problem and research team response is our conceptualization of social justice in the EdD. This looks like CR praxis informed by community questions; framed by CPAR as method and DiP as one of the products of this work. What we discuss here is no small feat, yet it is necessary to try to address the justice condition through conceptual, material, performative, and reflexive concerns in order to rise to Lupinacci's (2017) challenge.

\section{Lessons Learned}

Stovall's (CRSEA, 2020) articulation of critical race praxis that addresses conceptual, material, performative and reflexive concerns as a means of engaging with communities around a justice condition frames the avenues that we have taken in the work as a whole and in guiding our students toward a DiP project that is responsive to real needs in the community. In this section, we identify the lessons that we have learned thus far about essential elements for operationalizing this among a research team that includes EdD student researchers.

A strengths-based approach. A strong ongoing tenant of this work, starting from Timberly's initial report, on disproportionality in suspension, expulsion and arrests, is to take a strengths approach to inform research. This meant as researchers we were honest about our skill set and capacity and did not attempt to cross over into research or community programming outside of our realm of expertise. This is an important navigation of inviting the community in to fill the gaps, while maintaining a clear message of us all working together within our varied strengths to move this work forward. Joy, as a qualitative researcher applied her research expertise after Timberly had applied her quantitative research expertise,

demonstrating and naming for the community that we work within our strengths and invite the community to do the same. The intentionality behind asserting that the role and goal of researchers is to inform the dynamic work that communities are able to do, and not to lead, was liberating. Yet, it is an ongoing challenge to decenter one's self from perceptions of all-encompassing leadership status as university researcher.

This essential element is related to the material and reflexive concerns of the community (CRSEA, 2020). Consistent communication with and between working groups to identify who is best positioned to locate resources or speak to particular obstacles is an ongoing process that we assess and re-assess constantly as coPI's and as a leadership team in the network. For example, we consistently ask questions like: who is the best person to speak at a particular event? Or, who in the network has access to gatekeepers that make decisions about particular policies? Positioning ourselves as having defined limitations in our areas of expertise and skill-sets is an intentional move to model a strengths-based approach with graduate students who are learning to engage in research with/in communities.

Developing faculty conceptual understanding. To best support students in an activist-oriented DiP, it is critical that faculty work together toward common understandings of key concepts that will inform community-based research designs and conceptual frameworks. One important move to intentionally support students in their DiP journey at USI was to clearly define and discuss the "community" aspect of community-based leadership program which plays a critical role in informing the scope of a DiP in a communitybased educational leadership program. Graduate faculty who teach in the EdD program, collaborated on a definition for "community" which is informed by both time and space. As a faculty, we agreed that a community can have both shared and contradictory values and attitudes, yet the interconnected nature of a community means that communication, goals, and practices within the group will have direct and/or indirect influences on all of its members. While the concept of community is simultaneously simple yet elusive, as a program we seek to grapple with the complexities of what it might mean to become and remain a community-based educational leader. We prioritized human rights and agreed that equity and justice are the ultimate goal of community-based leadership. To that end, transformational leadership, relevant and grounded in real-world problems drives the work of community-based leaders. This approach is necessarily collaborative and means that leaders must work with and alongside community members to be agents of change so that educational access and excellence is realized in a community in ways that honor diversity of thought and experience. Ensuring that all faculty who will serve on dissertation committees have a common conceptual understanding of the diverse yet cohesive nature of community as it pertains to community-based research is related to Stovall's notion of conceptual concerns. In other words, if there is not a common (yet flexible) understanding of what is meant by community and the urgency of activism (which may impact questions around research protocols and timelines for example) among dissertation chairs or committee members, EdD students will struggle to find suitable committee members or successfully complete the program. This will for example drastically impact the ways in which conversations about and documents for the institutional review board at an institution are constructed or the ways that faculty will explain and advocate for students with faculty in or outside of their committees or departments.

\section{A communal approach to community research.}

\section{Because the primary goals of AndHowAreTheChildren are to effect} real change that improve the educational outcomes of Black children in a Midwestern city, these goals are anything but simple or shortterm. A communal approach to this work is necessary to address what Stovall (2020) names as the material and performative concerns of such a project. Material because of the limitations of an individual researcher or mentor to speak to all of the methods, skills, theories, or contextual information needed to address the problems of practice, and performative because there must be a consistent check-in between the community and researchers about the priorities, projects and communication resulting from the larger work. Racial disparities in school discipline and educational outcomes did not emerge in a vacuum, nor did they begin overnight. Therefore, the work to address these injustices must be sustained and dynamic enough to address the rapidly changing social realities that we are living through. For example, while a major focus of the school prison nexus work is about school discipline, since March of 2020 due to the COVID-19 crisis, there have been no expulsions or suspensions in a traditional sense. As a result, there must be new questions, explorations and resources to determine the ways in which inequity is present and the methods that we can create as a community to address those things. Being a part of a team of researchers and directly answering to community members who inform our inquiries situates future DiP to address real-world concerns, rather than individual or irrelevant research projects that could be completed in isolation. Given the context of this work as beginning in the community, by the community, the chances of sustained engagement where the university and community can partner in 
productive ways are increased. One concrete idea is to create written and restated community agreements that are used in working groups in the community (and that include expectations for researchers in the groups such as sharing airtime in conversations, identifying communication preferences for and between meetings) as well as standards of practice and communication among the research team (e.g., what can be shared or published, scheduling expectations for meetings). This communal approach has the potential to maximize learning and ensure that EdD students have opportunities to enhance their skills as change agents given that they will learn from their advisor and committee members, other students doing related work on the same larger project, and from community activists who are experts in a variety of areas.

\section{CONCLUSION}

In our conceptualization of scholarly activism, we assert that this work must be validated by the community, sustainable, malleable, and methodologically aligned with the goals and purposes set by the community. We take up activating activism in the EdD by providing an example from our ongoing CPAR project in a Midwestern city about the school prison nexus. We forward that a communal approach to CPAR work provides a platform for graduate students to engage in activist work with community that utilizes their growing research skills. This work is not for every faculty member, nor is it for every student. Alignment between student's professional goals, research orientation, life circumstances and commitments to the community must be considered carefully.

We recommend a deep and sustained engagement among both faculty and students interested in activist scholarship to consider Stovall's guiding principles for interrogating the conceptual, material, reflexive and performance concerns of the work. Although we have identified several lessons that we have learned thus far about the importance of a strengths-based approach, developing faculty's conceptual understandings and the power of a communal approach to community-based research, there is much to be learned. Further work around the institutional challenges of CPAR work specific to EdD programs, faculty experiences with individual or teams of researchers, the dynamics of community-university partnerships for EdD programs, and the types and decisions around presentation of CPAR findings within the community would be very important lines of inquiry.

In closing, activism and justice is not a short-term goal complete when articles are published or when dissertations are written. Activist scholarship is a long-term and ongoing commitment that neither begins nor ends in the university. If EdD programs aim to work toward equity goals for educators, students, families and communities, we must push beyond traditional modes of inquiry and build relationships with our students and communities that uphold a shared value in honoring and serving our fellow human beings.

\section{REFERENCES}

AERA. (2015, May, 06). Social justice in education award (2015) Lecture: Gloria Ladson-Billings. [Video]. YouTube. https://www.youtube.com/watch?v=ofB_t1oTYhl

Baker, T. L. \& Howard, J. (in press) "When I am honest about the whiteness of my childhood...": Interrupting white preservice teacher learned racialized silence. In Lopez \& Olan (Eds.). Re-Imagining transformative leadership in teacher education.
Baldridge, B. (2020). The youthwork paradox: A case for studying the community-based youth work in educational research. Educational Researcher, 1-8.

Baldridge, B. J., Beck, N., Medina, J. C., \& Reeves, M. A. (2017). Toward a new understanding of community-based education: The role of community-based educational spaces in disrupting inequality for minoritized youth. Review of Research in Education, 41(1), 381-402.

Boutte, G.S. (2016). Educating African American students: And how are the children? Routledge.

Capper, C. A., Theoharis, G., \& Sebastian, J. (2006). Toward a framework for preparing leaders for social justice. Journal of Educational Administration, 44(3), 209-224.

CRSEA Leadership. (2020, June 11) CRSEA: Dr. Ann Aviles interviews Dr. David Stovall on CRT Praxis in schools [Video]. YouTube. https://youtu.be/J-KFNhT0_nY

Douglas, T. R. M., \& Peck, C. (2013). Education by any means necessary: Peoples of African descent and community-based pedagogical spaces. Educational Studies, 49(1), 67-91.

Dumas, M. (2016). Against the dark: Antiblackness in education policy and discourse. Theory into Practice, 55, 11-19.

Fine, M. (2018). Just research in contentious times: Widening the methodological imagination. Teachers College Press.

Friere, P. (2000). Pedagogy of the oppressed (30th Anniv.). New York: Continuum.

Four Arrows (2017). Four ways to expand the foundation for CPED's social justice framework. Impacting Education: Journal on Transforming Professional Practice, 2, 28-32. https://doi.org/10.5195/ie.2017.28

George, P. (2017) Toward a social justice model for an EdD program in higher education. Impacting Education: Journal on Transforming Professional Practice, 2, 41-52. https://doi.org/10.5195/ie.2017.29

Horsford, S. D. (2012). This bridge called my leadership: An essay on Black women as bridge leaders in education. International Journal of Qualitative Studies in Education, 25(1), 11-22.

Jennings, M., \& Lynn. M. (2005). The house that race built: Toward a critical race analysis of critical pedagogy. Educational Foundations, 19(3-4), 15 32.

Johnson Jr., M. P. (2018). Community-Based participatory research through the lens of decision science. Retrieved from https://urbanresearchnetwork.org/community-based-participatoryresearch-through-the-lens-of-decision-science-by-michael-johnson/

Kirshner, B. (2015). Youth activism in the era of educational inequality. New York University Press.

Ladson-Billings, G., \& Tate, W. F. (1995). Toward a critical race theory of education. Teachers College Record, 97, 47-68.

Laura, C. T. (2014). Being bad: My baby brother and the school-to-prison pipeline. Teachers College Press.

Love, B. L. (2014). Urban storytelling: How storyboarding, moviemaking, and hip-hop-based education can promote students' critical voice. English Journal, 53-58.

Lupinacci, J. J. (2017). Addressing 21st century challenges in education. An ecocritical conceptual framework toward an ecotistical leadership in education. Impacting Education: Journal on Transforming Professional Practice, 2, 20-27. https://doi.org/10.5195/ie.2017.31

Lyiscott, J. (2014). 3 ways to speak English. TED Feb. https://www.ted.com/talks/jamila_lyiscott_3_ways_to_speak_english?lan guage $=\mathrm{en}$

Lyiscott, J. (2019). Black appetite. White food.: Issues of race, voice, and justice within and beyond the classroom. Routledge.

Noblit, G. W. (2004). Reinscribing critique in educational ethnography: Critical and postcritical ethnography. In K. B. DeMarrais \& S. D. Lapan (Eds.). Foundations for Research: Methods of Inquiry in Education and the Social Sciences, 181-201. Routledge.

Oakes, J., \& Rogers, J. (2005). Learning power: Organizing for education and justice. Teachers College Press.

Patel, L. (2016). Decolonizing Educational Research: From Ownership to Answerability. Routledge.

Porfilio, B.J., Strom, K., \& Lupinacci, J. (2019). Getting explicit about social justice in educational doctoral programs in the U.S.: Operationalizing an elusive construct in neoliberal times. The Journal of Educational Foundations, 32(1-4), 104-123. 
Stovall, D. (2006). Forging community in race and class: Critical race theory and the quest for social justice in education. Race ethnicity and Education, 9(3), 243-259.

Stovall, D. (2020). CRSEA: Dr. Ann Aviles interviews Dr. David Stovall on CRT Praxis in schools. June 11, https://www.youtube.com/watch?v=JKFNhTO_nY.

Strom, K., \& Porfilio, B. (2017) Centering social justice in EdD programs. Impacting Education: Journal on Transforming Professional Practice, 2, 16-19. https://doi.org/10.5195/ie.2017.43

Strom, K., \& Porfilio, B. (2017) Centering social justice in EdD programs. Impacting Education: Journal on Transforming Professional Practice, 2, 16-19. https://doi.org/10.5195/ie.2017.43

Torre, M. E. (2009). Participatory action research and critical race theory: Fueling spaces for nos-otras to research. The Urban Review, 41(1), 106120.

Warren, M. (2018). Research confronts equity and social justice: Building the emerging field of collaborative, community engaged education research. Urban Education, 53(4), 439-444.

Yamamoto, E. K. (1997). Critical race praxis: Race theory and political lawyering practice in post-civil rights America. Michigan Law Review, $821-900$

\section{FOOTNOTE}

1The authors use capital Black and lowercase white, following Dumas (2016) who explains "White is not capitalized in my work because it is nothing but a social construct, and does not describe a group with a common experience or kinship outside of acts of colonization and terror" (p. 13) 